\title{
Pre-mRNA splicing: from protein-coding to noncoding RNAs
}

\author{
ALBRECHT BINDEREIF \\ Institute of Biochemistry, University of Giessen, Heinrich-Buff-Ring 58, D-35392 Giessen, Germany
}

\section{Pre-mRNA splicing in the 1980s and 1990s}

Since I started in the pre-mRNA splicing field about three decades ago, I will beginn my little historical recollection at a somewhat earlier time than when the RNA journal started. To keep this somehow organized, I will summarize in decades, starting with the 1980s. What were significant changes in the RNA field over the past few decades? All of that from a very personal perspective.

My own research interests focus on mRNA splicing in the mammalian system and in trypanosomes. Although the balance between these two areas has changed over the years, it has been very rewarding, working in parallel on two widely different, evolutionarily very distant systems.

I was introduced to mRNA processing as a postdoc in Michael Green's laboratory (1984-88), at that time still a very small group at Harvard. Coming from my Ph.D. studies at UC Berkeley on the molecular biology of iron metabolism in bacteria, I was very grateful that I was given the opportunity to enter the RNA processing field, and that at a very exciting time. mRNA splicing was still a very young, emerging field: splicing and introns discovered only a few years before, and the first in vitro systems of mRNA splicing just developed, one of them in the Maniatis-Green labs.

My enthusiasm may reflect a general trend in these early days of mRNA processing: dissecting complex cellular processes by establishing in vitro systems, thereby obtaining access to the biochemical factors and understanding their mechanisms and interactions. My initial expectations were not disappointed: During my four postdoc years at Harvard I watched the discovery of the lariat structure, the first mutational analyses of splice signal sequences, the biochemical identification of the first mammalian protein splicing factors, the discovery of the spliceosome complex, and the initial insights into the complexities of alternative splicing: all discoveries that made it into today's textbook knowledge. Although not mentioned so far, the yeast Saccharomyces cerevisiae was used as a model system most successfully from the very beginning of the mRNA splicing research (and I am confident this will be covered by my yeast colleagues).

Corresponding author: Albrecht.Bindereif@chemie.bio.uni-giessen.de Article and publication date are at http://www.rnajournal.org/cgi/doi/ 10.1261/rna.050070.115. Freely available online through the RNA Open Access option.
After eight years in the United States, I moved back to Germany in 1988, with a dry-ice package of HeLa extracts and splicing constructs, to establish my own lab, as an independent group leader at the Max Planck Institute for Molecular Genetics in Berlin. I was fortunate to have all freedom of research as well as generous support by the Max Planck Society, at least for those six years (1988-94).

I pursued two lines of research, first, continuing postdoctoral projects on the mammalian snRNPs and their functions in splicing, using biochemical reconstitution as well as mutational approaches. Second, I decided to enter a new, related field: trans splicing in trypanosomes. Trans splicing in trypanosomes and nematodes had been discovered in the early 1980s, and constitutes an essential step in the maturation pathway of every protein-coding mRNA in trypanosomes. Surprisingly, by that time no in vitro system had been developed yet in trypanosomes; this became our initial goal (for many years), which, disappointingly, we never achieved. Instead, we succeeded in affinity-purifying trypanosome snRNPs, which gave us access to the first trypanosome splicing factors.

After these almost-paradisiac years at the Max Planck Society I had to find my way into the German university system, first at the Humboldt University of Berlin (199699), then, finally, as a Professor of Biochemistry, at the University of Giessen (since 1999). In the second half of the 1990s a lot of the general attention in the mRNA processing research shifted towards alternative mRNA splicing mechanisms and their underlying regulation depending on cell types, tissues, and development. Interests also began to focus more on disease-relevant changes of (alternative) splicing. My own projects reflected this, in that we investigated the role of a polymorphic, disease-relevant CA-repeat element in intronic gene regions, discovering its role in splicing regulation, including alternative splicing. We identified hnRNP L as the RNA-binding protein specifically recognizing CA-repeat and C/A-rich sequences, which became a major focus of my work over more than the next decade. HnRNPs had been known for decades, since the 1960s, and were considered for many years not very exciting pre-mRNA packaging factors. This changed in the 1980s, when it became clear

(C) 2015 Bindereif This article, published in $R N A$, is available under a Creative Commons License (Attribution-NonCommercial 4.0 International), as described at http://creativecommons.org/licenses/by-nc/4.0/. 
that an entire class of hnRNPs exists, and a decade later first interesting novel functions in alternative splicing appeared, which were systematically studied after 2000 .

\section{mRNA processing in the 2000s: alternative splicing, genomewide views, RNA bioinformatics}

By 2000, alternative splicing had become a booming field, with its own conferences and networks, for example our European EURASNET network, coordinated by Reinhard Lührmann, which I had the pleasure to participate in (2006-2011). Research focussed on the biochemical mechanisms that determine the regulation of alternative splicing and benefited very much from the rapid development of genomewide approaches: (splice-sensitive) microarray technology in the first years, soon to be replaced by the RNASeq deep-sequencing techniques established in this decade. RNA-Seq became a routine technology, which allowed us to monitor in a single experiment all alternative splicing changes, for example after knowdown of a specific regulator, or compare healthy and tumor tissue, or systematically establish a comprehensive atlas of alternative splice isoforms throughout the human body. The impact of this technological revolution can hardly be overstated: Many biological problems could be addressed and answered on a systemwide level and in a qualitative and quantitative manner, by designing experiments that rely on RNA-Seq measurements.

We used in my group these new possibilities as extensively as we could (and our budget allowed). As a consequence, applied bioinformatics ("RNA bioinformatics") became more and more important, a development that has accelerated since then. We applied it to describe the role of hnRNP L, one of our favorite splicing factors, but also to human U1C, considered a "general" splicing factor, which turned out to be relevant also in alternative splicing; we made exciting excursions to alternative splicing in zebrafish and mouse (possible through collaborative efforts), and applied the new RNA-Seq technology also in trypanosomes.

\section{mRNA processing in the 2010s: moving from protein-coding to noncoding RNAs}

Until 2000 only a few reports had appeared on single examples of noncoding RNAs. With the success of high-throughput RNA-Seq technologies, it became clear that these cases discovered over the last decades represent members of large classes of noncoding RNAs, widely different in sizes and functions, such as the miRNA and lncRNA families. As an example, the latest wave of this kind occurred in 2012/13, when circular RNAs (circRNAs) were (re)-discovered by the groups of Sharpless, Brown, and Rajewsky as a new and large family of noncoding RNAs, present in all eukaryotic systems examined, from yeast to human. The first circRNA examples date back to the discovery of plant-pathogenic viroid RNAs in the 1970s.
I personally consider the new circRNA class particulary fascinating: They are derived from single or multiple exons of pre-mRNAs, using a kind of alternative splicing for their excision. Thereby circRNAs connect the two worlds of protein-coding and noncoding RNAs, both generated by alternative pre-mRNA processing pathways. As a result, I decided for my own group to devote a major effort on these new questions posed by circRNAs: What factors and sequence determinants direct "normal" linear splicing versus circular splicing (generating mRNAs and circRNAs, respectively), what is involved in their cell-type and tissue-specific processing? Most importantly, what are the function of the hundreds to thousands of different circRNAs? Regarding human disease, what new opportunities do circRNAs offer as biomarker molecules in medical diagnostics, and can they open up new therapeutic strategies?

\section{Where to go in the future: integrating RNA biology disciplines, systems biology, and back to the bench}

Currently, we seem to live in a world of noncoding RNAs, dominated by RNA-Seq based technology. This development will likely continue, and we can be confident that more surprises and new noncoding RNA classes will appear in the next few years. In other words, the RNA world will become more populated and more complex.

What lags behind the initial quick discovery phase, are these questions: What are the functions of all these noncoding RNAs, and how do they integrate into our current view on gene expression? Are there unifying functions or endless diversity in each new class of noncoding RNAs? Most of this will require detailed, case-by-case studies, including some old-fashioned RNA biochemistry, which takes much more time and effort than the initial discovery ("back to the bench"). More complex issues will enter the RNA field, such as brain functions, synthetic biology, and more on human disease mechanisms. One prediction is easy to make: RNA bioinformatics will soon be equally important to experimental science, and new bioinformatic approaches will have to be developed to accomplish these integrative tasks; hopefully, this shift can also satisfied by a new generation of scientists in RNA-focussed systems biology.

My personal hope for the future is that new basic insight RNA biology will more easily translate into clinical applications. More research may also directly originate from disease-focussed questions, all to the benefit of better diagnosis and new therapies of human diseases.

Finally, on how RNA science is done and published: The RNA community - as far as I remember back-has a reputation of being highly critical with one's own as well as other people's work. I believe, this is the right way, even with today's emphasis on immediate public attention, high impact, and new surprises. If we stick to careful, scrupulous, and critical thinking and best scientific practice, I am looking forward to the bright and exciting future of RNA biology. 

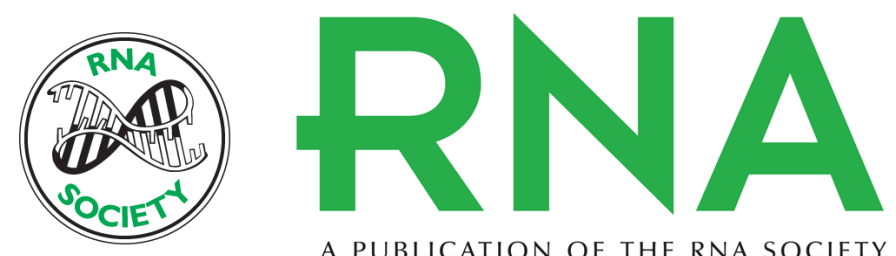

A PUBLICATION OF THE RNA SOCIETY

\section{Pre-mRNA splicing: from protein-coding to noncoding RNAs}

Albrecht Bindereif

RNA 2015 21: 571-572

Open Access Freely available online through the RNA Open Access option.

Creative This article, published in RNA, is available under a Creative Commons License Commons (Attribution-NonCommercial 4.0 International), as described at License http://creativecommons.org/licenses/by-nc/4.0/.

Email Alerting Receive free email alerts when new articles cite this article - sign up in the box at the Service top right corner of the article or click here. 